\title{
4D Mapping of the Fracture Evolution in a Printed Gypsum-Like Core by Using X-Ray CT Scanning
}

\author{
Huabo Liu $\mathbb{D}^{1,2}$ Fanjing Meng, ${ }^{1}$ and Shaozhen Hua ${ }^{1}$ \\ ${ }^{1}$ Henan Institute of Technology, Department of Mechanical and Electrical Engineering, Xinxiang 453003, Henan, China \\ ${ }^{2}$ College of Resources \& Safety Engineering, China University of Mining and Technology, Beijing 100083, China \\ Correspondence should be addressed to Huabo Liu; liuhuabo555@126.com
}

Received 18 August 2020; Revised 8 March 2021; Accepted 8 April 2021; Published 19 April 2021

Academic Editor: Wensu Chen

Copyright (c) 2021 Huabo Liu et al. This is an open access article distributed under the Creative Commons Attribution License, which permits unrestricted use, distribution, and reproduction in any medium, provided the original work is properly cited.

The paper presents the use of micro-X-ray computed tomography (CT) system and associated automatic loading device in visualizing and analyzing the propagation of penny-shaped flaw in gypsum-like 3D printing specimen. During the loading process, a micro-X-ray computed tomography (CT) system was used to scan the specimen with a resolution of $30 \times 30 \mu \mathrm{m}^{2}$. The volumetric images of specimen were reconstructed based on two-dimensional images. Thus, the propagation of penny-shaped flaw in gypsum-like 3D printing specimen in spatial was observed. The device can record the evolution of the internal pennyshaped flaw by X-ray CT scanning and the evolution of the surface crack by digital radiography at the same time. Fractal analysis was employed to quantify the cracking process. Two- and three-dimensional box-counting methods were applied to analyze slice images and volumetric images, respectively. Comparison between fractal dimensions calculated from two- and three-dimensional box-counting method was carried out. The results show that the fractal dimension increases with the propagation of cracks. Moreover, the common approach to obtain the 3D fractal dimension of a self-similar fractal object by adding one to its corresponding $2 \mathrm{D}$ fractal dimension is found to be inappropriate.

\section{Introduction}

Crack propagation and fracture of materials are directly related to the failure and catastrophic safety of structures in aerospace, transportation, chemical industry, machinery, energy, civil engineering, and other fields from the explosion of aerospace caused by low-stress brittle fracture of steel to the earthquake and tunnel instability caused by fracture of underground rock at various scales. All kinds of engineering disasters caused by concrete crack propagation, as well as human hard tissue damage such as tooth fracture and cortical bone fracture, are related to material crack propagation. This idea is also included in the ancient Chinese saying "the collapse of the wall must be due to its gap." Fracture mechanics is a special science to study the strength and crack propagation of materials with cracks or defects. It sprouted 100 years ago. Griffith published a classic paper on the brittle fracture of glass in 1920. The development of fracture mechanics theory has played a great role in the field of material and structural safety in various industries.

There is no way to create internal preset crack in $3 \mathrm{D}$ volume of one raw material, so artificial rock materials are introduced in rock mechanics experiments to study the principle of crack growth. Artificial rock materials are also more homogenous than raw materials. The attempted materials include glass [1], gypsum [2-7], ceramics [8], cemented materials $[9,10]$, and unsaturated transparent resin materials [11-13]. Transparent resin materials especially draw our attention since the cracking process of internal cracks can be observed directly. Adams and Sines [11] investigated three-dimensional elliptical-shaped flaw by PMMA, which is a kind of Plexiglas, and the experiment revealed that the principle of three-dimensional flaw propagation was more complex than predicted, under uniaxial compression. The tip of elliptical-shaped flaw is extended firstly and then generated huge fin-shaped crack on the two crack tip line. Dyskin et al. [8] used two approaches to insert internal penny-shaped flaw into unsaturated transparent resin materials 
and studied the propagation principle of one penny-shaped 3D flaw and double penny-shaped 3D flaw. The results demonstrated that the propagation of penny-shaped flaw is not the same with elliptical-shaped flaw: in the samples with pennyshaped flaw, they did not see the emergence of fin-shaped crack. Wong and Huang [14] systematically investigated the difference between elliptical flaw and penny-shape flaw using the same material as $[8,11]$ and confirmed their results. Fu and Zhu [12] used a new type of transparent resin which has a higher degree of brittleness to study the propagation and coalescence process of internal 3D penny-shaped flaw under uniaxial compression, and the test results showed that the fracture of internal 3D flaw produced a variety of cracks such as petal-shaped crack and finshaped crack. The results by using the unsaturated transparent resin from $[15,16]$ are similar to each other. However, those transparent materials have very different properties compared to rock $[17,18]$. Thus, the result exhibits a large deviation compared to the real rock. Therefore, a kind of rock-like material to make internal flaw is appealing.

In recent years, 3D printing technology is developing rapidly and has been applied to many fields, such as aerospace, medical science, military, automobiles, and construction. Some scholars have made some tentative exploration and achieved some results in rock mechanics, but still not fully systematic [19-23]. In the environment of consistent printing conditions, it can ensure that the printed specimen has consistent mechanical properties [20,24], so it is possible to manufacture samples that have the same properties, which bring inspiring news for rock mechanics. The application of 3D printing technology in rock mechanics may be able to solve the following problems, such as stress path problem of rock mechanic, preparing the rock mass sample with joint of the same surface morphology as that of the natural joint.

$\mathrm{X}$-ray computed tomography (CT) is a nondestructive means capable of analyzing rock fractures [25-27]. Some scholars use medical CT to monitor the crack growth of coal [28] which is very poor in accuracy and cannot monitor the crack growth visually. The minimum resolution of the scanner of X-ray computed tomography is $10 \mu \mathrm{m}$ for an object of $4.8 \mathrm{~mm}$. With the matching automatic loading device, we can visually see the crack propagation process. But there are few papers about investigation on crack propagation by X-ray computed tomography so that we have made a relevant attempt in this paper.

In this paper, a micro-X-ray CT system and the matching automatic loading device were used to investigate the internal penny-shaped flaw propagation of gypsum-like 3D printing sample to determine and quantify the damage and failure features accompanying with uniaxial compressive loading. Before uniaxial compressive loading test, the internal structure of the gypsum-like 3D printing sample was observed using the micro-X-ray CT system and scanning electron microscope. During uniaxial compressive loading, the device can record the evolution of the internal penny-shaped flaw by X-ray CT scanning and the evolution of the surface crack by digital radiography at the same time. After testing, the space morphology of the microcracking in the gypsum-like 3D printing samples was analyzed using the fractal method.
Two- and three-dimensional box-counting methods were applied to analyze slice images and volumetric rendering, respectively. Comparison between fractal dimensions calculated from two- and three-dimensional box-counting method was also carried out.

\section{3D Printing Procedure and Basic Characteristics of Specimens}

2.1. 3D Printing Procedure. The general 3D printing process includes four basic steps: (1) model construction, (2) file format conversion, (3) model printing, and (4) postprocessing. Korean scholars have found that printing options such as printing direction, printing layer thickness, binder saturation level, and postprocessing method can affect the mechanical property of the specimen [21]. Hence, in this printing process, we keep processes (3) and (4) unchanged to ensure that we can get the same mechanical properties of the specimens.

ProJet 660 from 3D Systems Inc. (http://www.3d-yizao. com) was used for the preparation of gypsum-like samples. The printing material includes a kind of gypsum-like powder and a kind of colorless and transparent binder. The composite of the powder mainly consists of $\mathrm{CaSO} 4 \cdot 0.5 \mathrm{H} 2 \mathrm{O}$. The accuracy of 3D printing of each layer of powder and binder is $0.09 \mathrm{~mm}$ thickness, which can ensure the accuracy of the gypsum-like samples.

2.2. Physical Characteristics of the Specimen. The experimental sample is a gypsum specimen produced by $3 \mathrm{D}$ printing technology, as shown in Figure 1(a). In this experiment, two types of samples are made: $25 * 50 \mathrm{~mm}$ standard cylinder and $25 * 50 \mathrm{~mm}$ cylinder with prefabricated coin cracks. In order to see internal cracks in 3D-printed gypsum samples, CT scans were performed on the gypsum samples. Figure 1(b) shows the reconstruction of the CT scan specimens, and Figures 1(c) and 1(d) show the longitudinal section of the standard specimens and coin cracks, respectively. The CT image is a digital image expressed in the gray scale, reflecting the dimensionless density of the material. The gray level of the image reflects the size of the density, the bright color is the high density material, and the dark color is the low density material. It can be seen that the grayscale of the image in Figure 1(c) is basically the same, that is, the gypsum particles in the standard sample are uniformly distributed, and the homogenous material can be considered in the millimeter scale. From Figure 1(d), it can be seen that the obvious color of the prefabricated coin-shaped cracks is dark, that is, the density is low, and the shape of the prefabricated coin-shaped crack is regular and clear. It shows that the $3 \mathrm{D}$ printing technology can make the complex cracks built in the rock. The prefabricated coin crack is located in the sample center, and the specific size is shown in Figure 1(d). The horizontal inclination $\Theta$ is $15^{\circ}$, the opening degree $h$ is $1 \mathrm{~mm}$, and the diameter $d$ is $10 \mathrm{~mm}$. It should be explained that the density of the 3D printing plaster sample is usually $1.2 \mathrm{~g} / \mathrm{cm}^{3}$, the natural density of the gypsum crystal is $2.3 \mathrm{~g} / \mathrm{cm}^{3}$, and the density of the $3 \mathrm{D}$ printing plaster sample is less compact. From the observation results of the scanning electron 
microscope (Figure 2), it can be seen that there are micrometer scale holes in the $3 \mathrm{D}$ printing plaster sample and the aggregation particles of gypsum crystals with different sizes from ten microns to dozens of microns. It is further proved the lack of compactness of 3D-printed gypsum samples and shows that 3D-printed gypsum samples exhibit heterogeneity at the micron scale.

\section{Experiment System and the Experiment Procedure}

3.1. Experiment System. We adopted the X-ray CT scanner called as ACTIS-225FFI $\mu \mathrm{CT}$, which is manufactured by BIR Corporation of USA, as shown in Figure 3(a). The equipment has strong applicability. It can scan specimen with a diameter up to $300 \mathrm{~mm}$, and at this point, its maximum resolution is $225 \mu \mathrm{m}$ (using $320 \mathrm{kV} \mathrm{X}$-ray system). The X-ray source is a $225 \mathrm{kV}$ Fein focus focal spot, which allows for resolution down to $5 \mu \mathrm{m}$ for an object of $8 \mathrm{~mm}$. However, the resolution under the conditions stated here is approximately $40 \times 40 \mu \mathrm{m}^{2}$. The scanner is operated at $110 \mathrm{KV}$ and $180 \mu \mathrm{A}$. The reconstruction matrix consisted of $1024 \times 1024$ pixels.

We designed and developed a wireless automatic loading and unloading device, which is used to support the ACTIS$225 \mathrm{FFI} \mu \mathrm{CT}$ system, and the control software system of wireless automatic loading test system based on virtual instrument is developed, as shown in Figure 3(b). The size of the loading device is $0.14 \times 0.14 \times 0.2 \mathrm{~m}$, and the loading device uses the motor-mechanical transmission loading system, which can control the loading process wirelessly in the control room. The device is suitable for the specimens whose size is $\varphi 25 \times 50 \mathrm{~mm}$ or $\varphi 50 \times 100 \mathrm{~mm}$, compared with similar equipment based on medical CT $[29,30]$. The instrument has a higher resolution, simple in structure, suitable for industrial CT vertical rotary table, good in rigidity, relatively cheaper, and can be carried out with static loading and dynamic loading. The device can be used in the test of the mechanical properties of the rock material under the condition of CT synchronous observation, such as uniaxial loading and unloading, Brazil splitting, and three-point bending. The device makes it possible to dynamically observe the failure process of the specimen under uniaxial compression. By combining the load-displacement curve and the crack initiation and propagation process of the specimen under uniaxial compression, we can get initiation time and cracking path of the specimen with flaw.

3.2. Experiment Procedure. At first, the AGS - H10 KG electronic universal testing machine is used to carry out uniaxial compression experiments on the samples. The displacement control loading mode is adopted, and the loading rate is set to $0.5 \mathrm{~mm} / \mathrm{min}$. The stress and strain curves of two types of samples and the failure forms are obtained. According to the results of the single axis experiment above, the industrial microfocus $\mathrm{CT}$ wireless automatic loading and unloading device was used to compress the sample of the coin-shaped cracked gypsum and to get the real-time CT scanning to obtain the crack propagation law of the built-in coin shape of the gypsum specimen under different stress states. Displacement control method for loading is limited by the matching wireless loader settings, and the loading rate is $0.6 \mathrm{~mm} / \mathrm{min}$. During the whole process, $\mathrm{X}$-ray penetrating photography was used to observe the development of sample surface and through crack. The acquisition frequency is $15 \mathrm{~Hz}$. Four fine scans were scanned to obtain the internal crack development of the sample. The fine scanning was carried out at the axial displacement $0.75 \mathrm{~mm}$, $1.2 \mathrm{~mm}, 2.0 \mathrm{~mm}$, and $2.28 \mathrm{~mm}$, respectively. The fine scanning time was about $24 \mathrm{~min}$.

\section{Experiment Results and Analysis}

4.1. Uniaxial Experimental Results. Figure 4 shows the stress and strain curves of the two types of samples under uniaxial compression loading. It can be seen that the uniaxial compressive strength of samples with internal coin cracks is lower than that of standard samples. The uniaxial compression strengths of the samples with built-in coin-shaped cracks and the standard samples are $2.89 \mathrm{MPa}$ and $4.67 \mathrm{MPa}$, respectively. The stress and strain curves of the two types of samples under uniaxial compression are smooth, and the stress-strain curves of the sample with coin-shaped cracks do not appear to be caused by the stress mutation caused by the crack propagation. Both types of samples have some residual strength under uniaxial compression loading. The residual strength of the standard sample peak is about $1 \mathrm{MPa}$, and the residual strength after the peak of the coin-shaped crack pattern is about $0.8 \mathrm{MPa}$.

Figure 5 shows the failure mode of two types of specimens under uniaxial compression. It can be seen that, under the uniaxial compression, the two types of specimens all present typical shear failure of rock materials, with an obvious oblique shear crack. It shows that 3D printing technology has certain feasibility in making rock material samples.

4.2. Experimental Results and Analysis of Microfocus CT Wireless Loader. The results are analyzed according to the video obtained from digital radiography and CT scanning of $\mathrm{X}$-ray industrial CT of sample with $15^{\circ}$ dip penny-shaped flaw. Figure 6 shows the surface crack growth of the sample with $15^{\circ}$ dip penny-shaped flaw. Figure 7 shows volumetric images at different stress states, which were reconstructed based on $2 \mathrm{D}$ slice images.

Figure 6 shows the surface crack appearance of specimen. At that time, the internal stress of the specimen is $\sigma=2.137 \mathrm{MPa}$ at $\varepsilon=0.0333$, which is obtained from curve of Figure 8 . From Figures $6(\mathrm{a})-6(\mathrm{~g})$, cracks gradually become larger, but Figure 6(h) is obviously larger than Figure 6(g). This is because no unloading was conducted during CT scanning, and crack is propagated automatically during CT scanning. At this point, the stress is obviously decreased.

Figure 7 shows the volumetric images at different stress states, which were reconstructed based on 2D slice images. CT image is a digital image with gray level representation. CT image is essentially a reflection of the dimensionless density of the specimen, the bright color is for high density material, and the dark color is for low density material. From the sectional view of Figure 7(a), we can clearly see the 


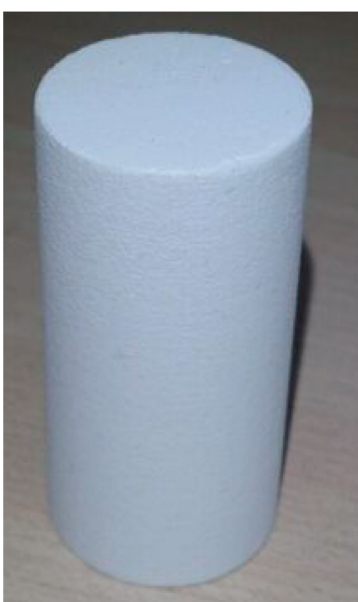

(a)

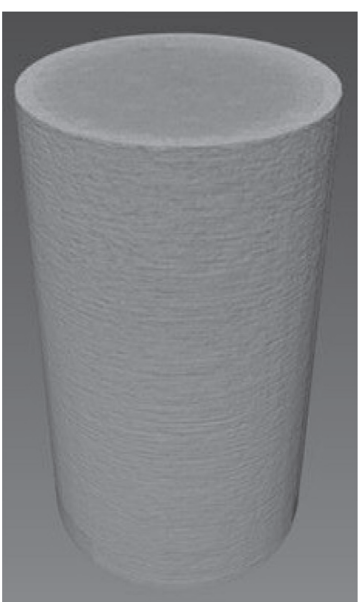

(b)

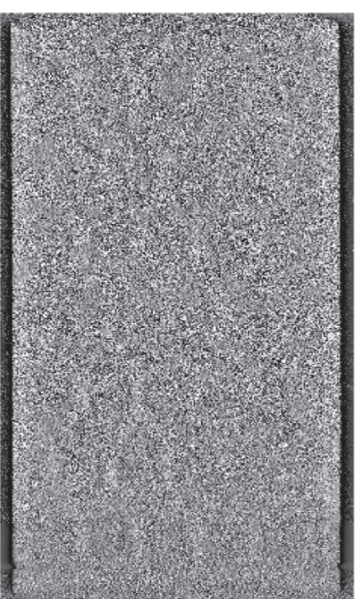

(c)

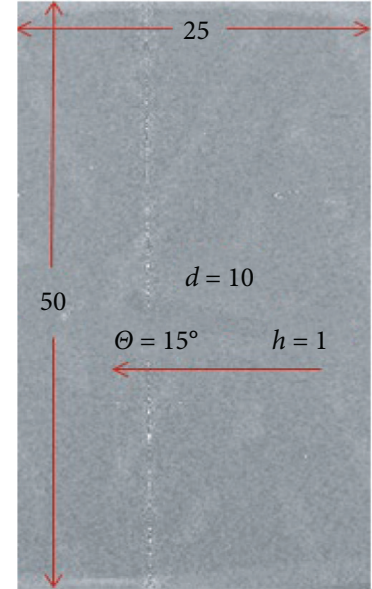

(d)

Figure 1: Gypsum samples of 3D printing. (a) Sample pictures, (b) reconstruction of the CT scanning sample, (c) profile of the CT scanning standard sample, (d) profile of the CT scanning sample with penny-shaped crack.

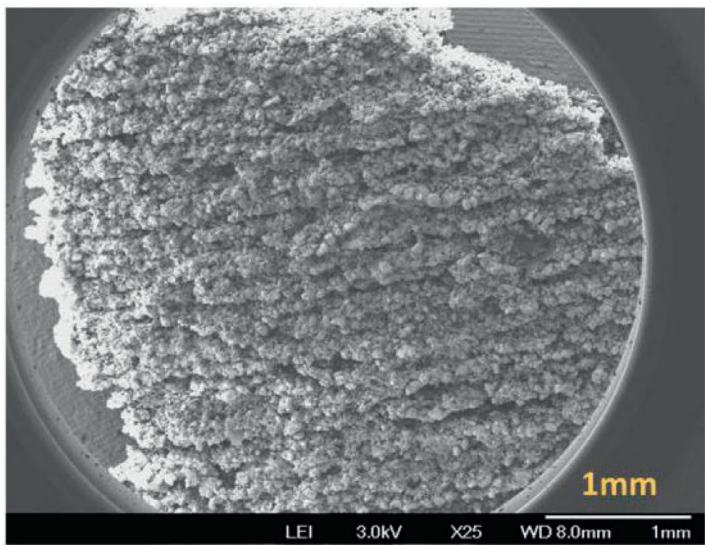

(a)

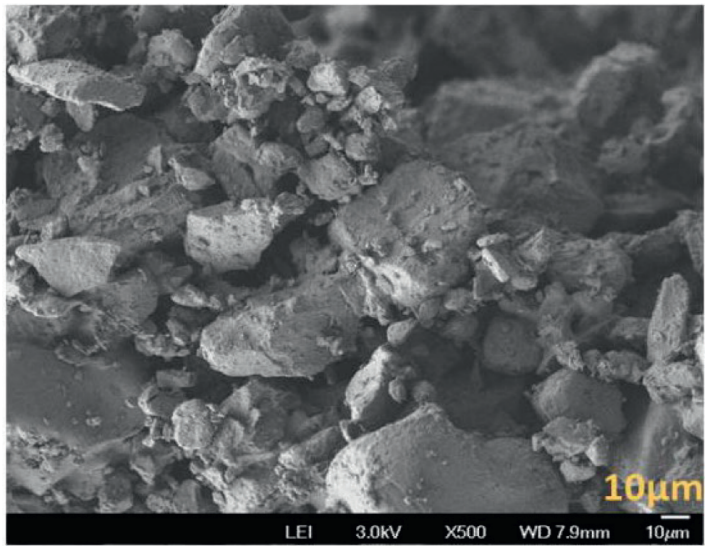

(c)

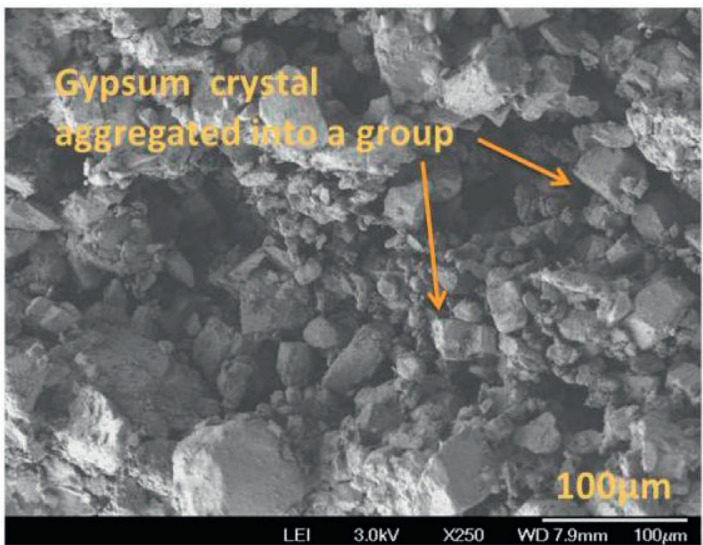

(b)

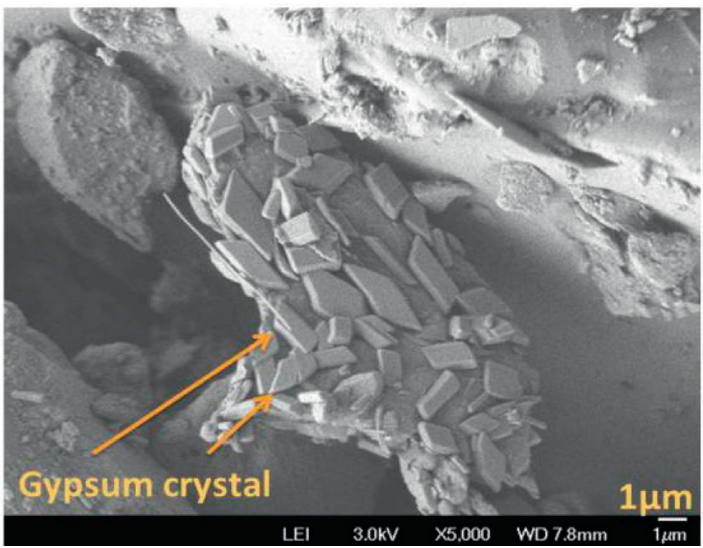

(d)

Figure 2: SEM images of the surface of the 3D printing gypsum sample. Resolution of (a) $1 \mathrm{~mm}$, (b) $100 \mu \mathrm{m}$, (c) $10 \mu \mathrm{m}$, and (d) $1 \mu \mathrm{m}$.

penny-shaped flaw in the center of the specimen, and a larger density of material is wrapped around the pennyshaped crack. There is no obvious change in the specimen at the stress state of $\sigma=1.54 \mathrm{MPa}$ before peak stress. We can see from Figure 7(b) that penny-shaped flaw becomes blurred at the stress state of $\sigma=2.08 \mathrm{MPa}$ before peak stress, and this is because penny-shaped flaw was compacted, but there are no other changes in the specimen. From Figure $7(\mathrm{c})$, at the 


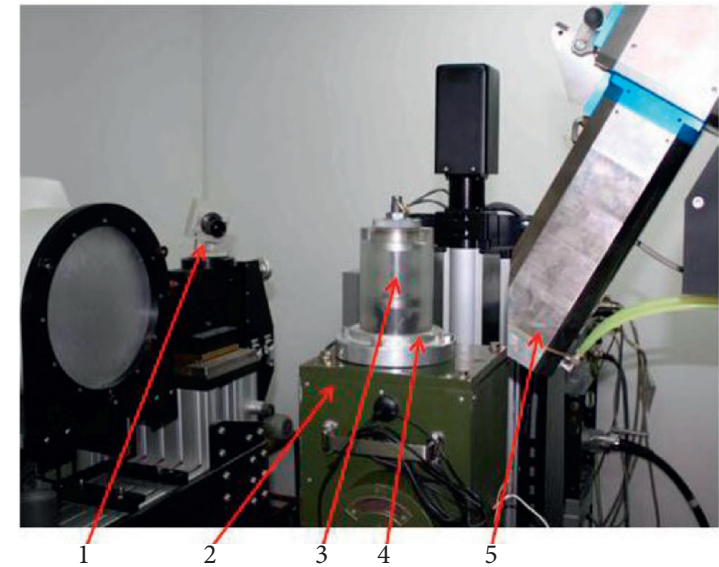

(a)

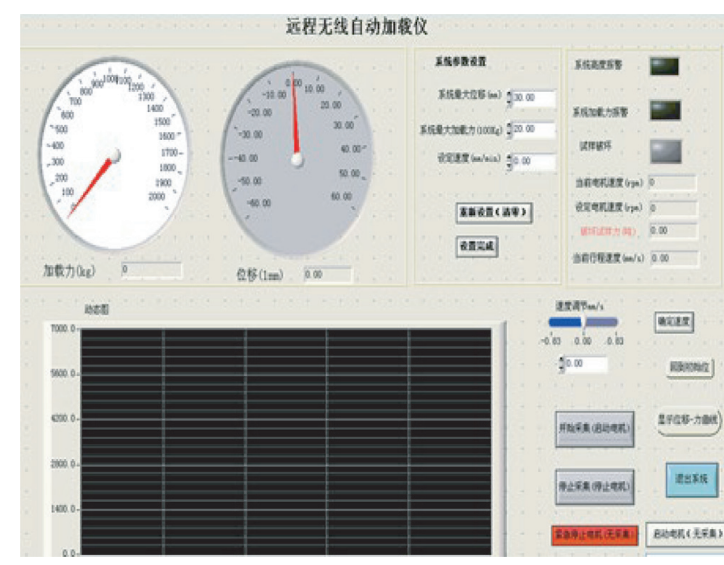

(b)

Figure 3: Automatic loading system with an industrial CT scanner and its control software interface. (a) Automatic loading system for rock core testing with an industrial CT scanner. (b) Control software interface of the automatic loading system.

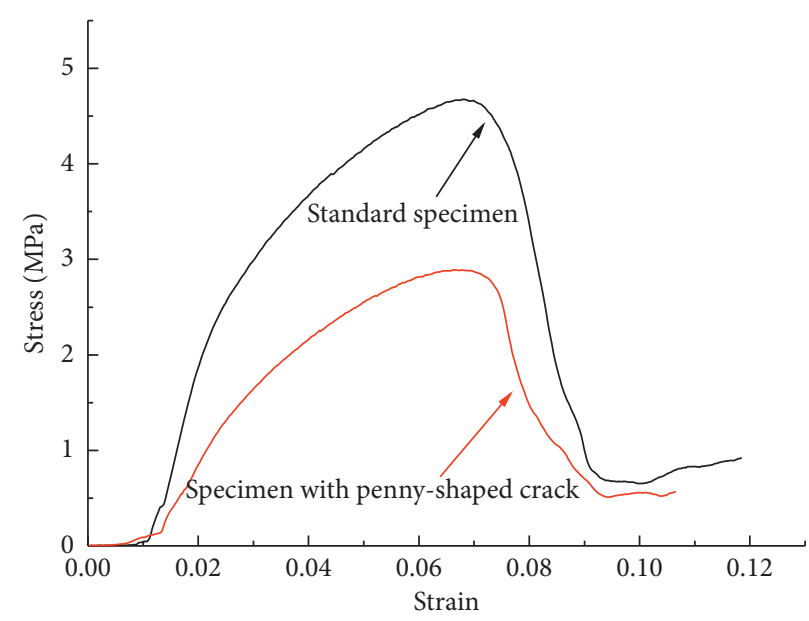

FIGURE 4: The stress-strain curves of two types of specimens under uniaxial compression.

beginning of the CT scanning, the stress in the specimen was $\sigma=2.18 \mathrm{MPa}$ after peak stress, but after CT scanning, the stress in the specimen was $\sigma=0.29 \mathrm{MPa}$, and the specimen basically has no bearing capacity and the structure of the specimen has been destroyed. The specimen was destroyed during CT scanning. Crack appearance at the location of the penny-shaped flaw was highly complicated, and it also can be seen from the latter part of the fractal analysis. Figure 7(d) was similar to Figure $7(\mathrm{c})$, though the opening of the crack became bigger.

\subsection{Fractal Analysis of Images Using the Box-Counting} Method. Through the careful observation, measurement and analysis of the fracture morphology, crack propagation path, and the distribution of dislocations, we have found that the fractal can be used to quantitatively characterize the fracture morphology and crack growth path. Since [31] first used fractal quantitative analysis of the metal fracture surface, there have been a lot of research and exploration study on the fractal characteristics of the fracture surface of different materials [32-35]. In this study, 2D and 3D box-counting method were applied to measure the $D$ values of scanned slice images and reconstructed $3 \mathrm{D}$ volumetric images. The power law relationship defines the $D$ of a fractal as follows [36]:

$$
N(\delta)=a \cdot \delta^{-D} \text {. }
$$

Here, $N(\delta)$ denotes the minimal number of cubes of size $\delta$ covering the fractal object. It follows that a larger $N(\delta)$ or $D$ should cover a more irregular fractal object. Equation (1) can be rewritten in the form of a line which means that the value of $D$ can be estimated from the slope of the line:

$$
\ln (N(\delta))=-D \cdot \ln (\delta)+\ln a .
$$

4.3.1. Calculation of Fractal Dimension for 2D Images. According to the above mathematical definition, we used mathematical software MATLAB to calculate the fractal figures of each image. Figure 9 illustrates the computational 


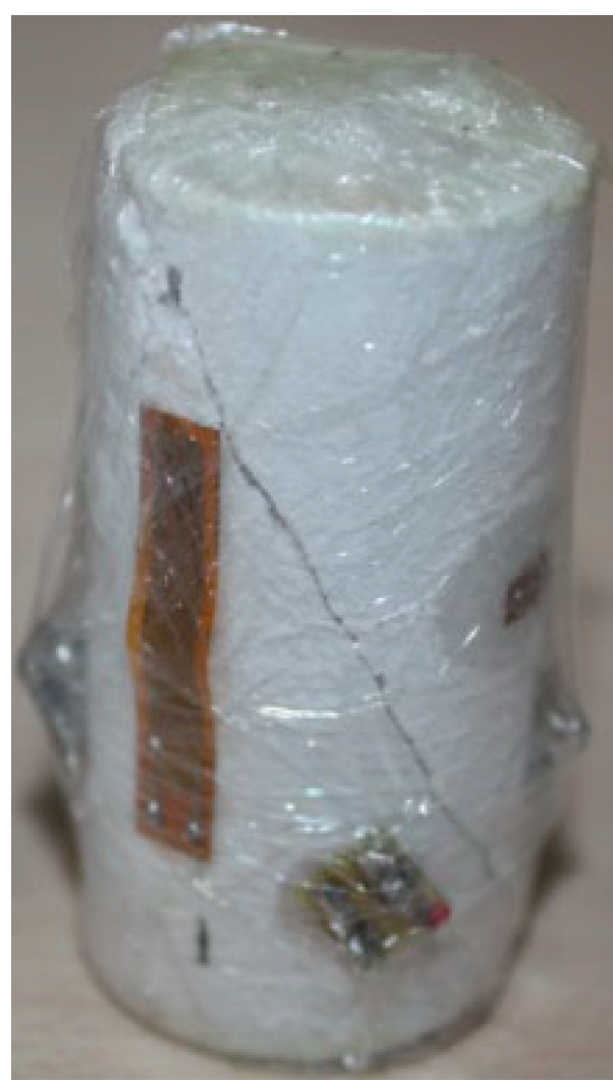

(a)

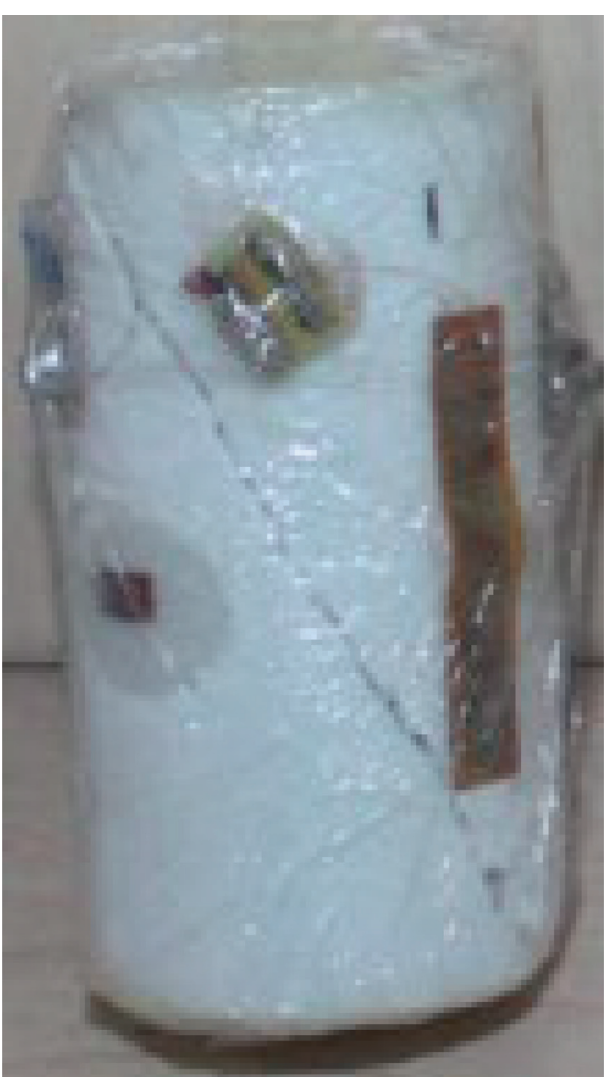

(b)

Figure 5: Failure mode after uniaxial compression of two types of specimens. (a) Standard specimen. (b) Specimen with penny-shaped crack.

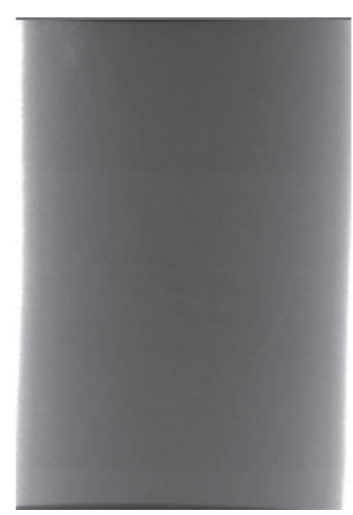

(a)

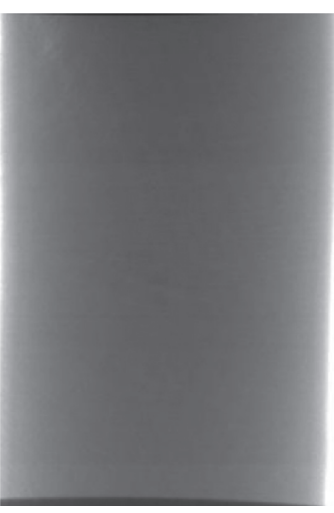

(b)

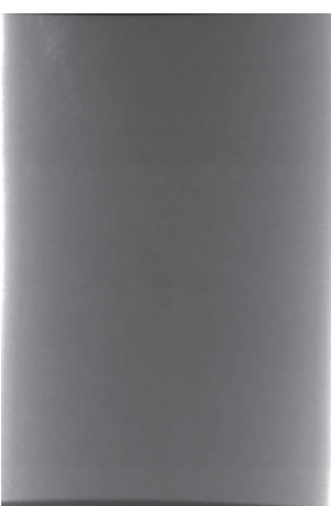

(c)

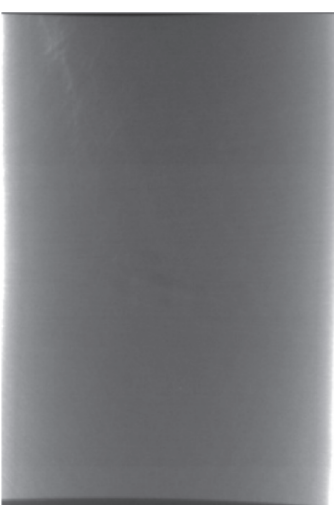

(d)

Figure 6: Continued. 


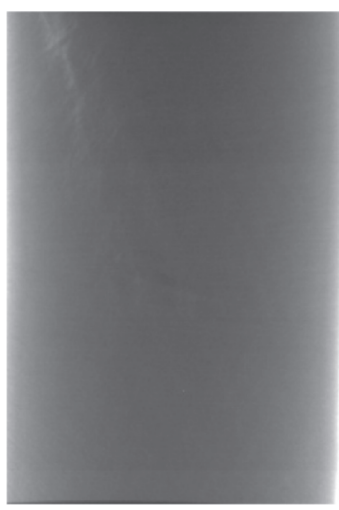

(e)

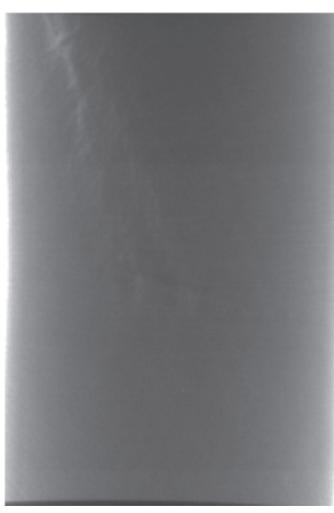

(f)

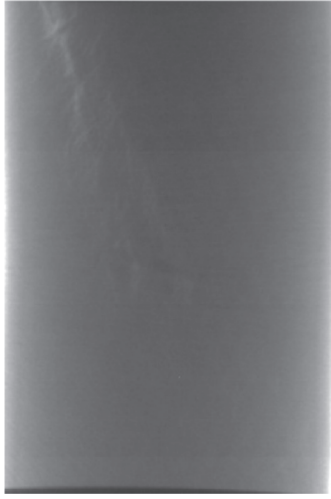

(g)

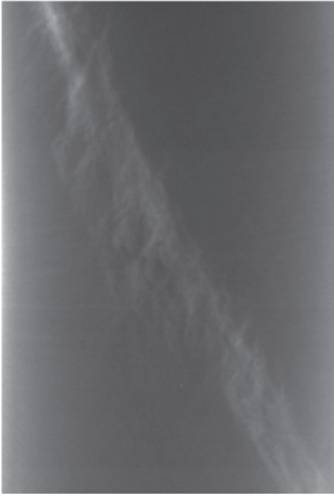

(h)

FIGURE 6: Surface crack appearance of the 3D printing gypsum specimen with penny-shaped flaw: (a) $2.137 \mathrm{MPa} 0.0333$; (b) $2.217 \mathrm{MPa}$ 0.0340 ; (c) $2.178 \mathrm{MPa} 0.0348$; (d) $2.257 \mathrm{MPa} 0.0357$; (e) 2.177 MPa 0.0365; (f) $2.137 \mathrm{MPa} 0.0371$; (g) 2.057 MPa 0.0376; (h) 0.299 MPa 0.0400.

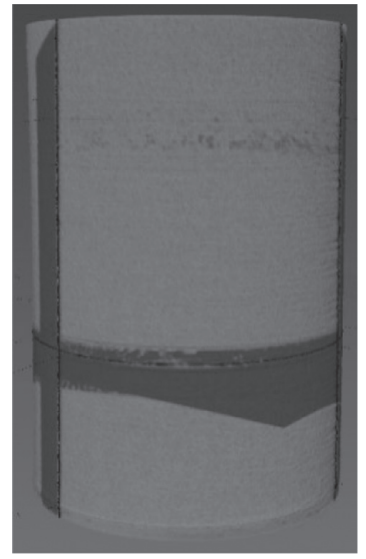

Front view

(a)

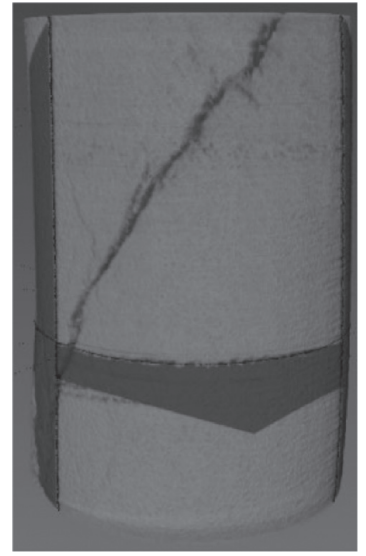

Front view

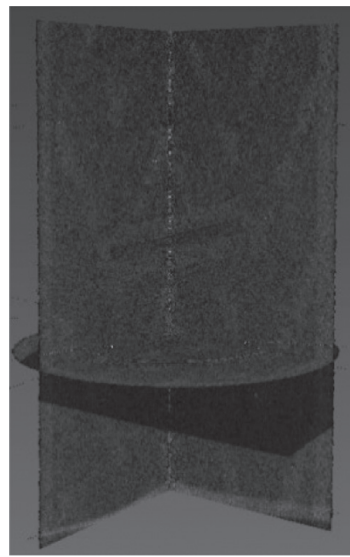

Sectional view

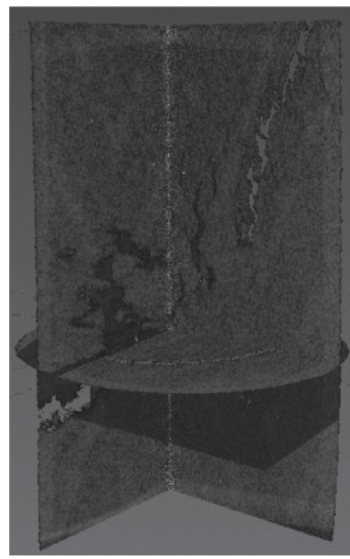

Sectional view

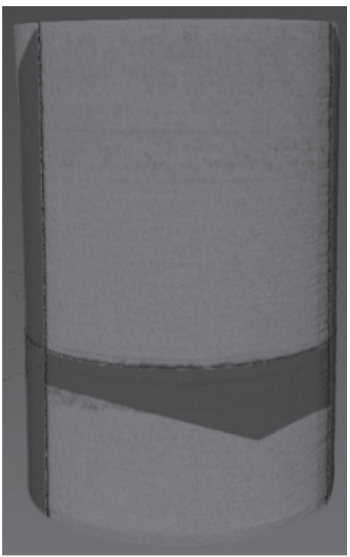

Front view

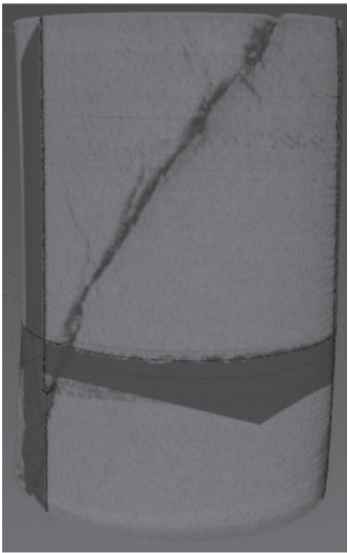

Front view

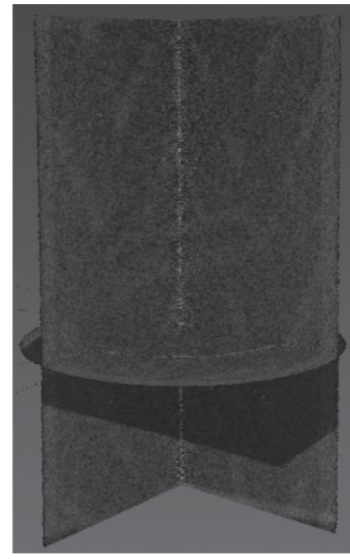

Sectional view

(b)

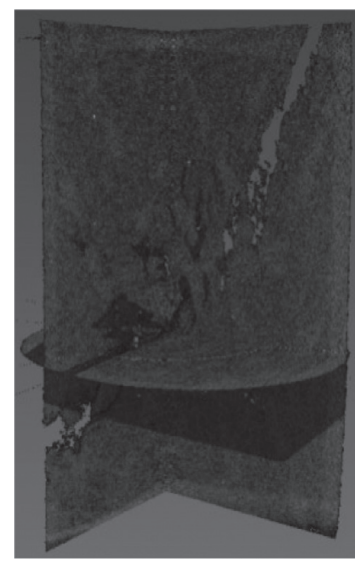

Sectional view

(c)

(d)

FIGURE 7: Internal crack evolution of the 3D printing gypsum specimen with penny-shaped flaw. (a) $\sigma=1.54 \mathrm{MPa}, \varepsilon=0.015$, and $\sigma c=2.26 \mathrm{MPa}$; (b) $\sigma=2.08 \mathrm{MPa}, \varepsilon=0.024$, and $\sigma c=2.26 \mathrm{MPa}$; (c) $\sigma=2.18 \mathrm{MPa}, \varepsilon=0.040$, and $\sigma c=2.26 \mathrm{MPa}$; $(\mathrm{d}) \sigma=0.52 \mathrm{MPa}, \varepsilon=0.046$, and $\sigma c=2.26 \mathrm{MPa}$. 


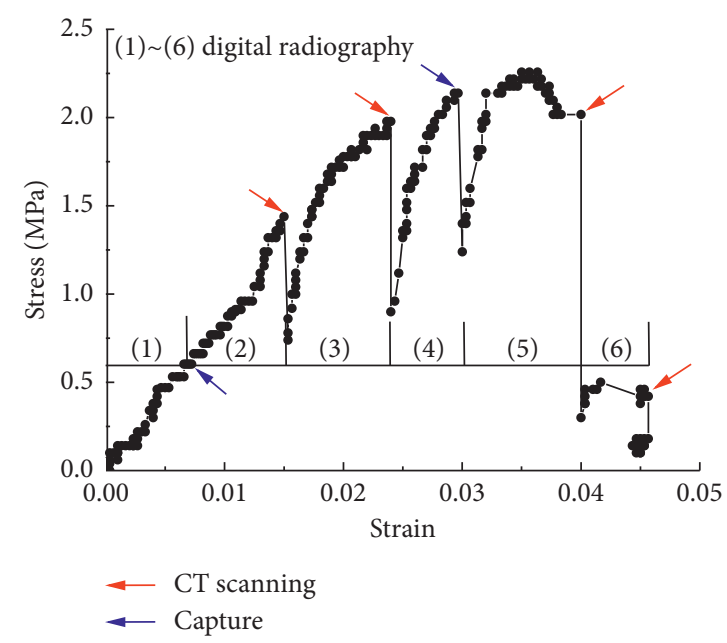

FIgURE 8: Stress-strain curve of the 3D printing gypsum specimen with CT automatic loading device.

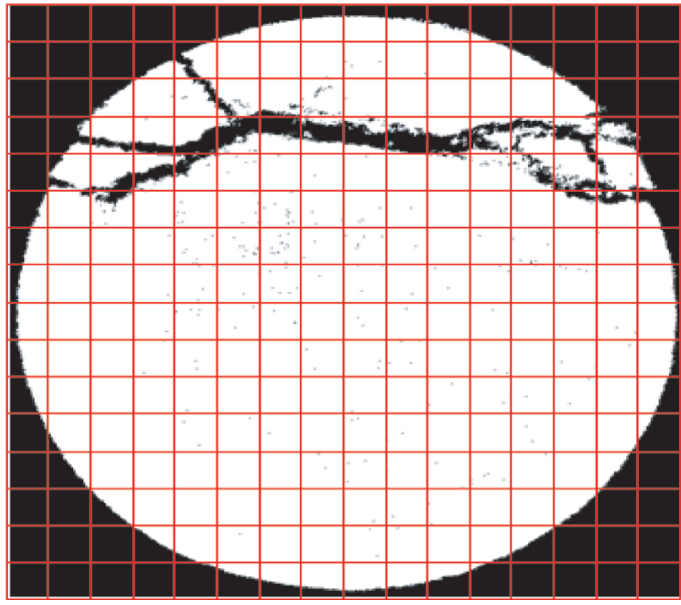

(a)

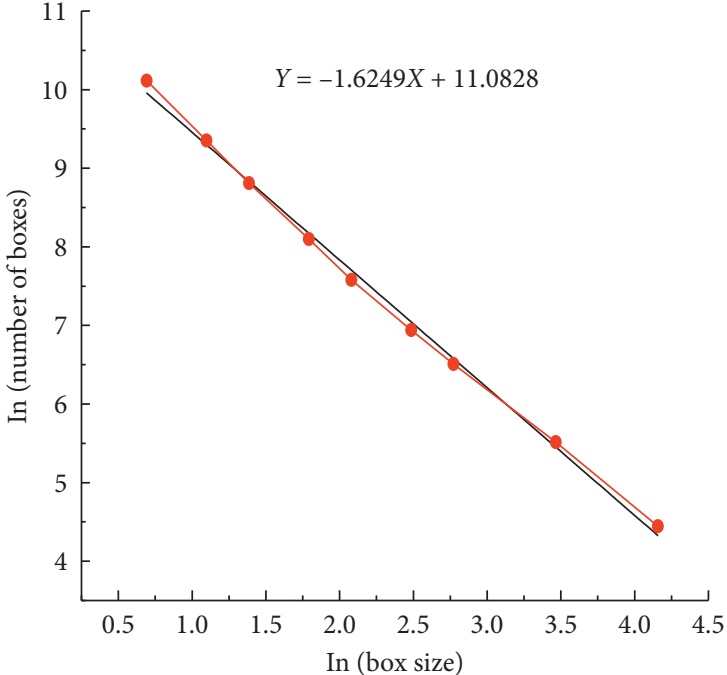

(b)

Figure 9: (a) The image of a slice with cracks covered by grids. (b) Estimated result of $D$ for one slice at $0.52 \mathrm{MPa}$ in postfailure of the specimen.

procedure for $D$ estimation and $D$ estimated result for one slice at $0.52 \mathrm{MPa}$ after failure of the specimen.

The fractal dimensions of different scanned slices as the stress reaches $1.54 \mathrm{MPa}, 2.08 \mathrm{MPa}, 2.18 \mathrm{MPa}$, and $0.52 \mathrm{MPa}$ are shown in Figures 10(a)-10(d). It is found that the fractal dimensions of different scanned slices at the stress of 1.54 MPa and 2.08 $\mathrm{MPa}$ prefailure stage give the identical regularity, and at the stress of $2.18 \mathrm{MPa}$ and $0.52 \mathrm{MPa}$ postfailure stage, the fractal dimensions of different scanned slices have similar law.

The fractal dimension $(D)$ is a quantitative indicator of object complexity. It can be seen that the value of fractal dimension in the upper region of the penny-shaped flaw and the lower region of the penny-shaped flaw is obviously bigger than the value of other slices in Figure 10. It indicates that a large number of microcracks are developed in the upper and lower region of the penny-shaped flaw as the stress reaches $2.18 \mathrm{MPa}$, as also can be seen in Figure 7.

It is evident that the fractal dimension of slice varies with the spatial positions as show in Figure 11. The fractal dimension increases with the cracking expansion and bifurcation and decreases with coalescence of cracks. Theoretically, the fractal dimension of the cracks in specimen rises gradually with the stress increasing in the prefailure stage, but decreases at the postfailure stages. In the current test, there is no obvious crack growth in the specimen in the prefailure stage. The fractal dimension is close to 1.58 in the prefailure stage when the stress was $1.54 \mathrm{MPa}$ and near 1.56 when the stress was $2.08 \mathrm{MPa}$. The fractal dimension increased in the postfailure stage when the stress was $2.18 \mathrm{MPa}$ and $0.52 \mathrm{MPa}$, to approximately 1.63 and 1.65 in the postfailure stage, respectively. The features of fractal dimension were obtained based on the analysis of hundreds of slices of images. 


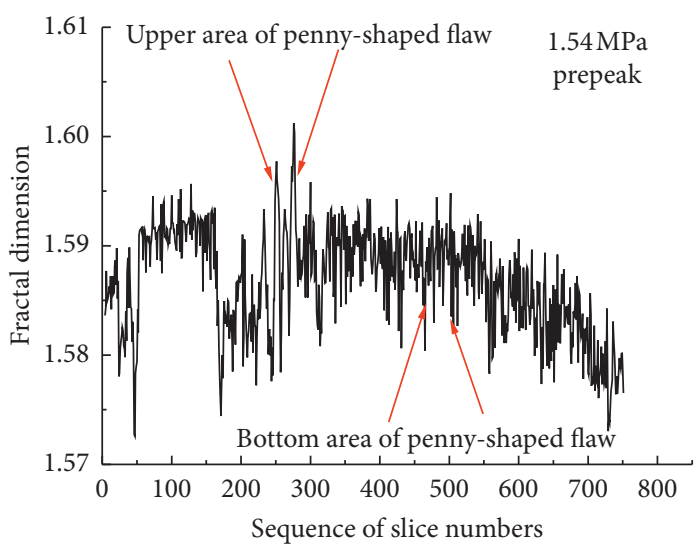

(a)

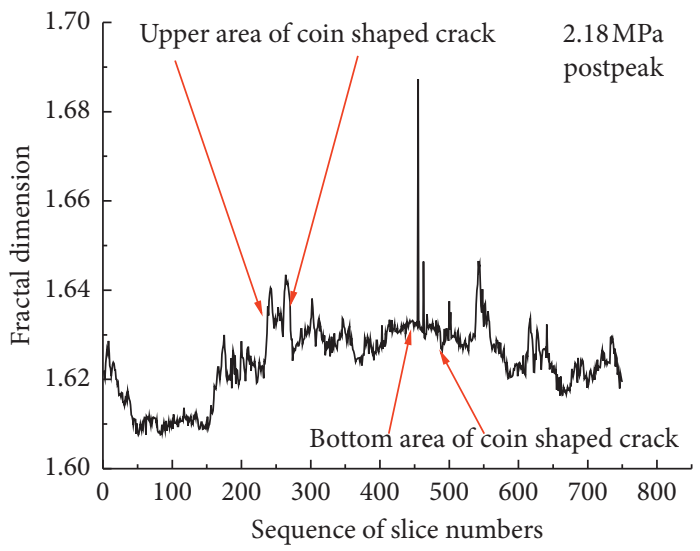

(c)

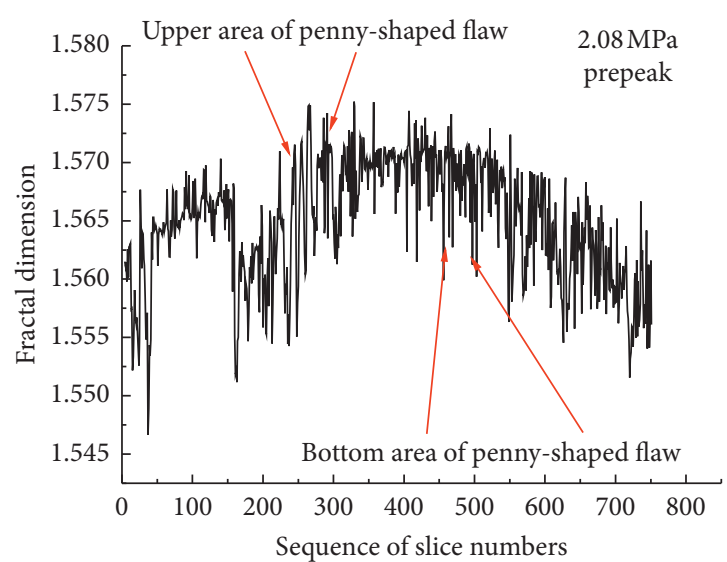

(b)

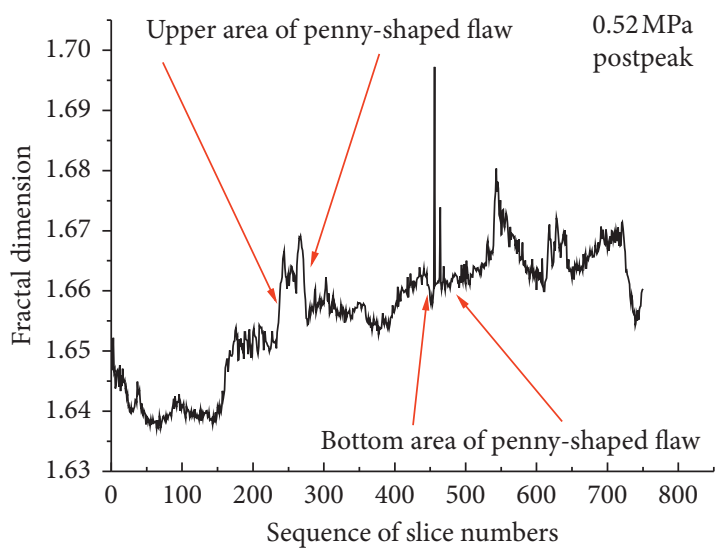

(d)

Figure 10: Calculation results of $D$ for the scanned slices at four stress states.

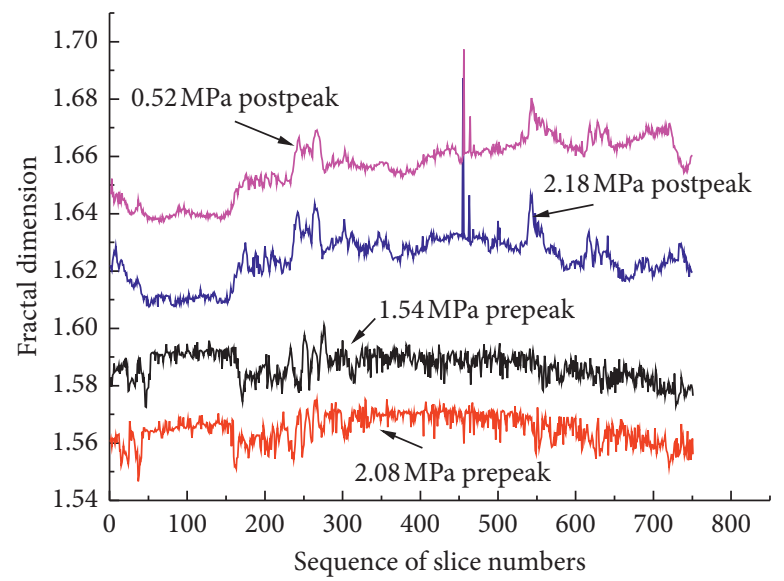

FIgURE 11: Calculation results of $D$ for the scanned slices at four stress states.

4.3.2. Fractal Dimension Calculation for $3 D$ Images. Using a similar program by MATLAB software, the fractal dimension of the volume is calculated as shown in Figure 12. Table 1 shows the results calculated based on the 3D boxcounting method. It is found that the 3D fractal dimension decreases with the stress increasing at the prefailure stage and then increases at the postfailure stage.
Comparison analysis was conducted to the estimated fractal dimension based on the 2D and $3 \mathrm{D}$ box-counting methods. It is identified that the common approach to obtain the 3D fractal dimension of a self-similar fractal object by adding one to its corresponding $2 \mathrm{D}$ fractal dimension is found to be inappropriate. The result shows that the volumetric fractal dimension of cracks is a little bit lower 


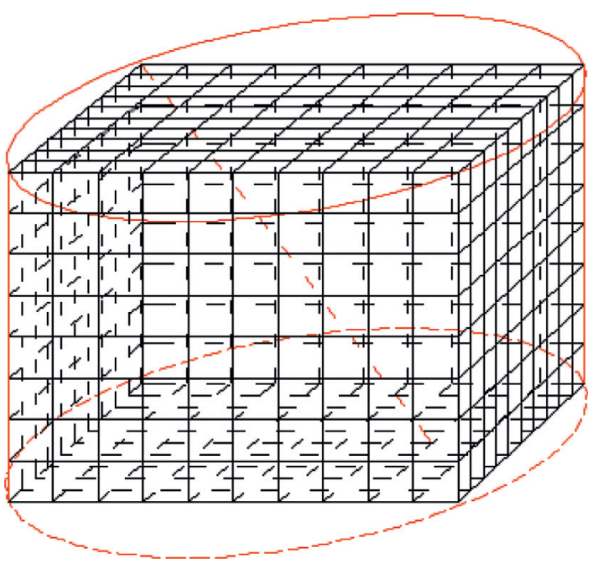

(a)

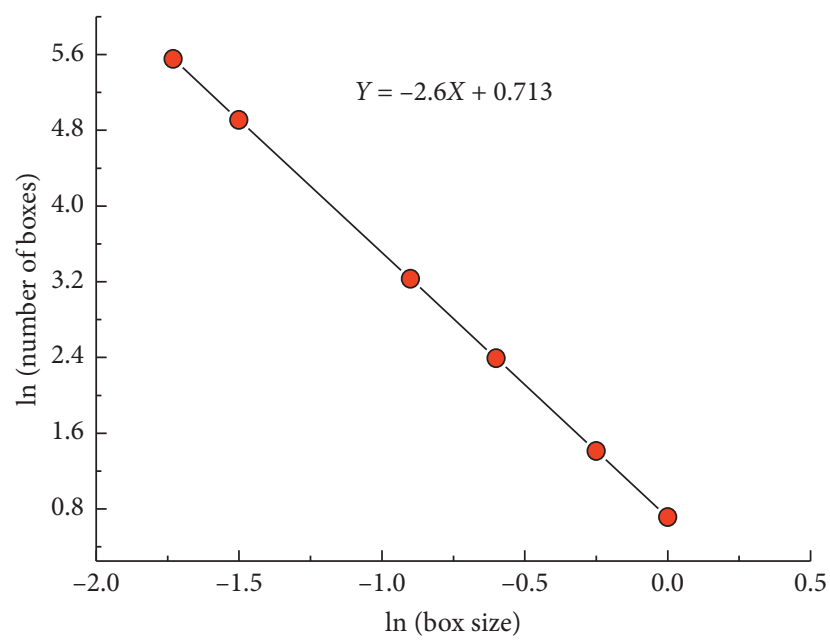

(b)

FIgURE 12: Illustration of computational procedure for volumetric $D$ estimation and $D$ estimated result as stress reaches $2.18 \mathrm{MPa}$. (a) The $3 \mathrm{D}$ boxes (black uniform mesh) are used to cover the core. (b) Estimated result of volumetric $D$ as stress reaches $2.18 \mathrm{MPa}$.

TABLe 1: Estimation results of fractal dimension based on box-counting method.

\begin{tabular}{lccc}
\hline Stress $(\mathrm{MPa})$ & Average $D$ of slices $(\mathrm{ADS})$ & ADS +1 & Volumetric $D$ \\
\hline 1.54 & 1.587 & 2.587 & 2.55 \\
2.08 & 1.565 & 2.565 & 2.532 \\
2.18 & 1.625 & 2.625 & 2.6 \\
0.52 & 1.66 & 2.66 & 2.63 \\
\hline
\end{tabular}

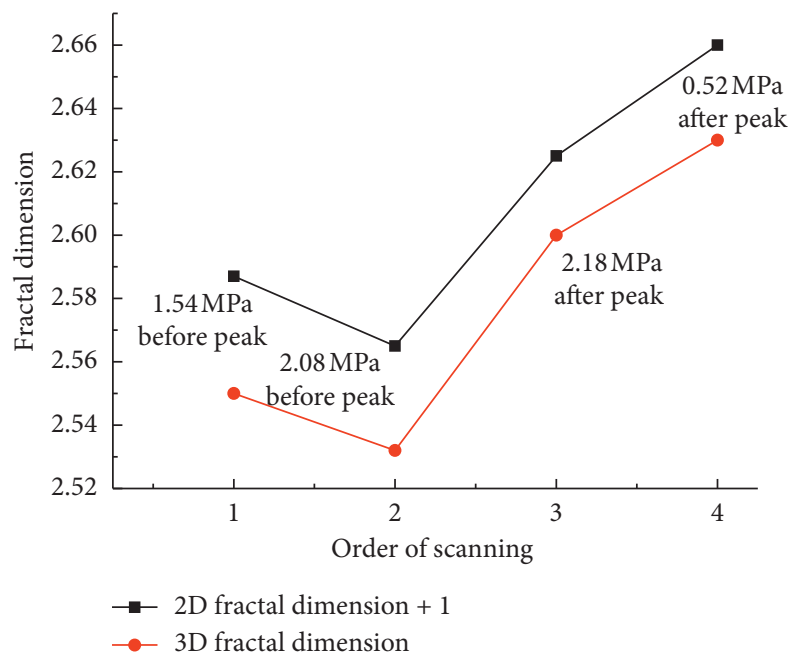

Figure 13: Comparison of $D$ calculated by two- and three-dimensional box-counting method.

than $2 \mathrm{D}$ fractal dimension obtained by slice image analysis added to one, which is consistent with the conclusions of [37], but inconsistent with the conclusion of [38].
Nevertheless, as the stress increases, the difference between these two types of fractal dimensions keeps approximately the same which is 0.03, as shown in Figure 13. 


\section{Conclusions}

This paper demonstrates the application of 3D printing on internal penny-shaped flaw cracking and failure process. The specimens, originated from a powder-based material and a kind of colorless and transparent binder, were produced using 3DP technique. Firstly, the basic physical and mechanical properties (i.e., UCS strength, density, and internal and surface topography) of 3D printing specimens with $15^{\circ}$ dip angles were obtained from the axial compressive tests, CT scanning, and SEM tests. Secondly, a micro-X-ray CT system and the associated automatic loading device were used to visualize and analyze the propagation of penny-shaped flaw in gypsum-like $3 \mathrm{D}$ printing specimen under uniaxial compressive condition. During the loading process, a micro-X-ray computed tomography (CT) system were used to scan the specimen four times with a resolution of $30 \mu \mathrm{m} \times 30 \mu \mathrm{m}$, i.e., two times before stress peak and two times after stress peak. The volumetric images of specimen were reconstructed based on two-dimensional images. Thus, the propagation of penny-shaped flaw in gypsum-like 3D printing specimen in spatial was observed. The device can record the evolution of the internal pennyshaped flaw by X-ray CT scanning and the evolution of the surface crack by digital radiography at the same time. Fractal analysis was employed to quantify the cracking process. Twoand three-dimensional box-counting methods were applied to analyze slice images and volumetric images, respectively. Comparison between fractal dimensions calculated from the two-dimensional and three-dimensional box-counting method was carried out. The results show that the fractal dimension increases with the propagation of cracks. Moreover, the common approach to obtain the 3D fractal dimension of a fractal object by adding one to its corresponding 2D fractal dimension is found to be inappropriate [39].

\section{Data Availability}

The data used to support the findings of this study are included within the article.

\section{Conflicts of Interest}

The authors declare that they have no conflicts of interest.

\section{Acknowledgments}

The research was financially supported by the Key Scientfic Research Projects of Henan Universities (nos. 21A130001 and 21A110007) and the Scientific and Technological Research Projects in Henan Province (no. 212102210432). The authors specially thank Gaofeng Zhao for the suggestions and aiding in the analysis of the data.

\section{References}

[1] E. Hoek and Z. T. Bieniawask, "Brittle fracture propagation in rock under compression," International Journal of Fracture, vol. 1, pp. 137-155, 1965.

[2] O. Reyes and H. H. Einstein, "Failure mechanisms of fractured rock-a fracture coalescence model," in Proceedings of the 7th
ISRM International Congress on Rock Mechanics, pp. 333-340, Aachen, Germany, September 1991.

[3] B. Shen, O. Stephansson, H. H. Einstein, and B. Ghahreman, "Coalescence of fractures under shear stresses in experiments," Journal of Geophysical Research: Solid Earth, vol. 100, no. B4, pp. 5975-5990, 1995.

[4] X. Z. Sun, B. Shen, Y. Y. Li, B. L. Zhang, and N. Jiang, "Retracted article: laboratory study of three-dimensional crack propagation in rock-like material under uniaxial compression," Rock Mechanics and Rock Engineering, vol. 49, no. 10, p. 4211, 2016.

[5] L. N. Y. Wong and H. H. Einstein, "Crack coalescence in molded gypsum and carrara marble: Part 1. Macroscopic observations and interpretation," Rock Mechanics and Rock Engineering, vol. 42, no. 3, pp. 475-511, 2008.

[6] L. N. Y. Wong and H. H. Einstein, "Crack coalescence in molded gypsum and carrara marble: Part 2-microscopic observations and interpretation," Rock Mechanics and Rock Engineering, vol. 42, no. 3, pp. 513-545, 2008.

[7] L. N. Y. Wong and H. H. Einstein, "Systematic evaluation of cracking behavior in specimens containing single flaws under uniaxial compression," International Journal of Rock Mechanics and Mining Sciences, vol. 46, no. 2, pp. 239-249, 2009.

[8] A. V. Dyskin, E. Sahouryeh, R. J. Jewell, H. Joer, and K. B. Ustinov, "Influence of shape and locations of initial 3-D cracks on their growth in uniaxial compression," Engineering Fracture Mechanics, vol. 70, no. 15, pp. 2115-2136, 2003.

[9] H. Haeri, K. Shahriar, M. F. Marji, and P. Moarefvand, "Cracks coalescence mechanism and cracks propagation paths in rock-like specimens containing pre-existing random cracks under compression," Journal of Central South University, vol. 21, no. 6, pp. 2404-2414, 2014.

[10] H. Haeri, "Experimental and numerical study on crack propagation in pre-cracked beam specimens under threepoint bending," Journal of Central South University, vol. 23, no. 2, pp. 430-439, 2016.

[11] M. Adams and G. Sines, "Crack extension from flaws in a brittle material subjected to compression," Tectonophysics, vol. 49, no. 1-2, pp. 97-118, 1978.

[12] J. W. Fu and W. S. Zhu, "Experimental study on numerical simulation of propagation and coalescence process of a single three-dimensional flaw in rocks," Journal of China Coal Society, vol. 38, no. 03, pp. 411-417, 2013.

[13] L. N. Germanovich, R. L. Salganik, and A. V. Dyskin, "Mechanisms of brittle fracture of rock with pre-existing cracks in compression," Pure and Applied Geophysics, vol. 143, no. 3, pp. 117-149, 1994.

[14] R. WongM. Huang et al., "Growth and coalescence of three-dimensional cracks under uniaxial compression," in Proceedings of the 39th US Rock Mechanics Symposium of Soil and Rock, pp. 901-908, Cambridge, UK, June 2003.

[15] A. V. Dyskin and L. N. Germanovich, "A model of crack growth in microcracked rock," International Journal of Rock Mechanics and Mining Sciences \& Geomechanics Abstracts, vol. 30, no. 7, pp. 813-820, 1993.

[16] A. V. Dyskin, R. J. Jewell, H. Joer, E. Sahouryeh, and K. B. Ustinov, "Experiments on 3D crack growth in uniaxial compression," International Journal of Fracture, vol. 65, no. 4, pp. 77-83, 1994.

[17] S. Melin, "When does a crack grow under mode II conditions," International Journal of Fracture, vol. 30, pp. 103-114, 1986. 
[18] S. Melin, "Why are crack paths in concrete and mortar different from those in PMMA," Materials and Structures, vol. 22, pp. 23-27, 1989.

[19] S. Fereshtenejad and J. J. Song, "Fundamental study on applicability of powder-based 3D printer for physical modeling in rock," Rock Mechanics and Rock Engineering, vol. 201610 pages, 2016.

[20] C. Jiang and G.-F. Zhao, "A preliminary study of 3D printing on rock mechanics," Rock Mechanics and Rock Engineering, vol. 48, no. 3, pp. 1041-1050, 2014.

[21] C. Jiang, G.-F. Zhao, J. Zhu, Y.-X. Zhao, and L. Shen, "Investigation of dynamic crack coalescence using a gypsum-like 3D printing material," Rock Mechanics and Rock Engineering, vol. 49, no. 10, pp. 3983-3998, 2016.

[22] Q. Jiang, X. Feng, L. Song, Y. Gong, H. Zheng, and J. Cui, "Modeling rock specimens through 3D printing: tentative experiments and prospects," Acta Mechanica Sinica, vol. 32, no. 1, pp. 101-111, 2016.

[23] Y. Ju, H. Xie, Z. Zheng et al., "Visualization of the complex structure and stress field inside rock by means of $3 \mathrm{D}$ printing technology," Chinese Science Bulletin, vol. 59, no. 36, pp. 5354-5365, 2014.

[24] H. B. Liu, Y. X. Zhao, Y. D. Jiang et al., "Experimental study of mechanical properties of 3D printing gypsum specimens," Mechanics in Engineering, vol. 39, no. 5, pp. 455-459, 2017.

[25] G. Viggiani, N. Lenoir, P. Besuelle et al., "X-ray microtomography for studying localized deformation in fine-grained geomaterials under triaxial compression," Comptes Rendus Mecanique, vol. 332, no. 10, pp. 819-826, 2004.

[26] K. H. Wolf, Van Bergen, F. R. Ephraim, and H. Pagnier, "Determination of the cleat angle distribution of the RECOPOL coal seams, using CT-scans and image analysis on drilling cuttings and coal blocks," International Journal of Coal Geology, vol. 73, pp. 259-272, 2008.

[27] Y. Zhao, S. Liu, G.-F. Zhao, D. Elsworth, Y. Jiang, and J. Han, "Failure mechanisms in coal: dependence on strain rate and microstructure," Journal of Geophysical Research: Solid Earth, vol. 119, no. 9, pp. 6924-6935, 2014.

[28] H. M. Zhao, Y. Yang, Y. Zhang, and L. Fan, "Fine test on progressive fracturing process of multi-crack rock samples under uniaxial compression," Chinese Journal of Rock Mechanics and Engineering, vol. 29, no. 3, pp. 465-470, 2010.

[29] X. R. Ge, "Deformation control law of rock fatigue failure, real-time X-ray CT scan of geotechnical testing, and new methed of stability analysis of slopes and dam foundations," Chinese Journal of Geotechnical Engineering, vol. 30, no. 1, pp. 1-20, 2008.

[30] W. Tian, F.-N. Dang, W.-H. Ding, and X.-Y. Liang, "Development of dynamic loading apparatus for CT experiment and its applicaton," Rock and Soil Mechanics, vol. 31, no. 1, pp. 309-313, 2010.

[31] B. B. Mandelbrot, D. E. Passoja, and A. J. Paullay, "Fractal character of fracture surfaces of metals," Nature, vol. 308, no. 5961, pp. 721-722, 1984.

[32] T. D. Babadagli, "Fractal characteristics of rocks fractured under tension," Theoretical and Applied Fracture Mechanics, vol. 39, pp. 73-88, 2003.

[33] R. W. Cahn, "Fractal dimension and fracture," Nature, vol. 338, no. 6212, pp. 201-202, 1989.

[34] V. C. Saouma, "Fractal characterization of concrete crack surfaces," Engineering, Fracture Mechanics, vol. 35, no. 1, 1990.
[35] V. E. Saouma and C. C. Barton, "Fractals, fractures, and size effects in concrete," Journal of Engineering Mechanics, vol. 120, no. 4, pp. 835-854, 1994.

[36] H. P. Xie and Z. D. Chen, "Fractal geometry and fracture of rock," Acta Mechanica Sinica, vol. 20, no. 3, pp. 265-271, 1988.

[37] D. Tang and A. G. Marangoni, "3D fractal dimension of fat crystal networks," Chemical Physics Letters, vol. 433, no. 1-3, pp. 248-252, 2006.

[38] C. S. Lu and W. S. Han, "Fractal mechanism of spallation and relation between fractal dimension and coalescence threshold," Acta Mech. Sin.vol. 27, no. 1, pp. 28-37, 1995.

[39] D. A. Lange, H. M. Jennings, and S. P. Shah, "Relationship between fracture surface roughness and fracture behavior of cement paste and mortar," Journal of the American Ceramic Society, vol. 76, no. 3, pp. 589-597, 1993. 